\title{
FARDA \& "COR": \\ UM ESTUDO RACIAL NAS PATENTES \\ DA POLÍCIA MILITAR DA BAHIA
}

Jaime P. Ramalho Neto*

$\mathrm{P}$

roponho neste artigo analisar o ingresso dos oficiais policiais militares baianos, a mobilidade na hierarquia policial militar e a ocupação de funções de prestígio e mando na Polícia Militar do Estado da Bahia (PMBA). ${ }^{1}$ Discuto, inicialmente, a produção de teóricos das ciências sociais acerca da noção de raça e racismo e as desigualdades socioculturais, focalizando a ascensão social e o preconceito como obstáculos à mobilidade social. ${ }^{2}$ Em seguida, discuto os elementos-chave para a ascensão nas patentes da PMBA.

No período pós-Abolição, cientistas argumentavam uma visão calcada na antropometria; as afirmações demonstravam uma inferioridade dos africanos, a partir dos traços fenotípicos (cor da pele, lábios grossos, textura do cabelo), e uma capacidade degenerada de reprodução de seus descendentes, que influenciaria a composição do povo brasileiro.

Mestre em Estudos Étnicos e Africanos pela Universidade Federal da Bahia.

1 Este artigo é uma versão de parte de minha dissertação de mestrado "Farda \& cor: mobilidade nas patentes e racismo na Polícia Militar da Bahia" (Universidade Federal da Bahia, 2008).

2 Utilizo o conceito de cor associado aos traços fenótipos, à tonalidade da pele, com destaque para os descendentes de africanos, e que remete a um status inferior que produz preconceitos com suas crenças prévias nas qualidades morais, físicas e psicológicas; criam uma desvantagem competitiva geracional para os negros e seus descendentes. Quanto à cor, ver, por exemplo, Antonio Sergio Guimarães, "Raça”, racismo e grupos de cor no Brasil", Estudos AfroAsiáticos, n. 27 (1995), pp. 45-63; sobre mobilidade, ver Carlos Hasenbalg e Nelson do Vale Silva, Estrutura social, mobilidade e raça, Rio de Janeiro: IUPERJ/Vértice, 1988. 
Também deve ser observado que, nesse período, havia uma preocupação governamental com a mão de obra de ex-escravos, pois o país ingressava no processo de industrialização e necessitava, enquanto nação, ser visto como um "povo civilizado", 3 e com padrão de conhecimento e urbanidade segundo o modelo eurocêntrico. ${ }^{4}$

Contrapondo as pesquisas das relações étnico-raciais dos cientistas com formação jurídica e médico sanitarista, outros estudiosos buscaram mostrar a contribuição dos negros para a formação da sociedade brasileira, e destacavam ainda a convivência harmoniosa; ${ }^{5}$ estas diferentes etnias ou raças no Brasil comporiam, segundo Da Matta, a "fábula das três raças", ${ }^{6}$ sem que houvesse conflitos explícitos, diferente do racismo one drop rule norte-americano. ${ }^{7}$

Bastide e Fernandes, ${ }^{8}$ além de Van den Berghe, ${ }^{9}$ procuraram compreender as restrições da ascensão social dos afro-brasileiros, percebendo que os estereótipos negativos como os traços fenótipos demarcavam um lugar no mercado de trabalho. Tais manifestações do racismo brasileiro, segundo os autores, afetavam um expressivo segmento de pessoas de cor, que estavam inscritas em ocupações não intelectuais, com baixo acesso à educação, e reproduziam uma sub-representação no preenchimento de posições na estrutura de classe.

Tais estudos procuravam mostrar que, na sociedade brasileira, as desigualdades e o preconceito racial se evidenciam como remanescentes de uma ordem racial pós-escravista. A passagem de uma sociedade

3 Oliveira Vianna, Evolução do povo brasileiro, Rio de Janeiro: Livraria José Olympio / São Paulo: Editora Nacional, 1933; Raimundo Nina Rodrigues, Os africanos no Brasil, Brasília: Universidade de Brasília, 2004. Destacamos estes autores por entenderem raças como antropologicamente distintas, hierarquizando-as, e onde aparecem, entre outros atributos, a descendência e a moral numa perspectiva eugênica.

4 Para uma análise das combinações das teorias de interpretação do darwinismo social e da perspectiva evolucionista e monogenista no Brasil, ver Lílian Schwarcz, O espetáculo das raças: cientistas, instituições e questão racial no Brasil - 1870-1930, São Paulo: Companhia das Letras, 1993.

5 Gilberto Freire, Casa grande \& senzala, Rio de Janeiro: José Olympio, 2000.

6 Roberto da Matta, Relativizando: uma introdução antropologia social, Rio de Janeiro: Ed.Rocco, 1987.

7 Donald Pierson, Brancos e pretos na Bahia: estudo de contato racial, São Paulo: Companhia Editora Nacional, 1971, pp.198-209.

8 Roger Bastide e Florestan Fernandes, Brancos e negros em São Paulo: ensaio sociológico sobre aspectos da formação, manifestação atuais e efeitos do preconceito de cor na sociedade paulistana, São Paulo: Companhia Editora Nacional, 1956.

9 Pierre L. Van Den Bergh. Race and Racism (A Comparative Perspective), Nova York: [s.e.], 1967. 
de status para uma de contrato, as desigualdades com base nos atributos da cor da pele ou na origem étnica perderiam força como argumentaram Florestan Fernandes e Costa Pinto $;^{10}$ de modo que essa visão otimista da sublimação do problema racial brasileiro desconsiderou as dinâmicas raciais no país, ao prever o desaparecimento do racismo e da intolerância calcada nos atributos físicos.

No final da década de 70, a noção de raça aparece como uma concepção analítica para explicar a desigualdade entre negros e brancos, no que se refere à renda, à educação e à ocupação. A raça surge como um atributo socialmente elaborado, que desqualifica e cria uma desvantagem competitiva para os negros e seus descendentes. ${ }^{11}$

Desse modo, a ideologia racial brasileira atuaria de forma refinada ao se utilizar da cor, dos atributos físicos e somáticos, para classificar depreciativamente os indivíduos, estabelecendo uma hierarquia social própria da multirracial sociedade brasileira. Assim, destacaram Skidmore e Guimarães, vendo que ocorreu uma naturalização da condição subalterna dos negros e de seus descendentes, pela combinação da cor à raça, ao status e à classe, aportando valores morais, intelectuais e culturais de maneira depreciativa. ${ }^{12}$

Nesse sentido, segundo Dávila, ${ }^{13}$ a ideologia racial brasileira concebida na eugenia privilegiava do modelo racial do branco europeu, por ver os indivíduos portadores de qualidades intelectuais, pela "boa aparência" e pela "competência", pressupostos para inclusão ou exclusão em atividades como o exercício do magistério.

${ }^{10}$ Florestan Fernandes, A integração do negro na sociedade de classes, São Paulo: Ática, 1978. Luiz de A. Costa Pinto, O negro no Rio de Janeiro: relações de raça numa sociedade em mudança, Rio de Janeiro: Ed. UFRJ, 1998.

11 Hasenbalg e Vale Silva, Estrutura social, mobilidade e raça. Esta obra e outras de Hasenbalg permitem verificar que a categoria raça deixa de ser vista como rígida e imutável, mas fluida e dinâmica, que opera com mecanismos de inclusão e exclusão contra os não brancos, como apontaram Jefferson Bacelar em A hierarquia das raças: negros e brancos em Salvador, Salvador/Rio de Janeiro: Pallas, 2001; e Paula Cristina da Silva, Negros à luz dos fornos: representações do trabalho e da cor entre metalúrgicos baianos, São Paulo: Dynamis Editorial / Bahia: Programa A Cor da Bahia, 1997.

12 Thomas Skidmore, O Brasil visto de fora, Rio de Janeiro: Paz e Terra, 1994; Guimarães, "'Raça', racismo e grupos de cor no Brasil", pp. 45-63.

13 Jerry Dávila, Diploma de brancura: política social e racial no Brasil - 1917-1945, São Paulo: UNESP, 2006. 
De modo que, a cor surge para o branco como uma vantagem na ocupação de melhores posições sociais, já para os negros e seus descendentes, como um acúmulo de desvantagens de geração a geração. $\mathrm{O}$ status ocupacional serve como indicador da posição do indivíduo no sistema de estratificação social, a partir da origem social e dos níveis educacionais que o qualificam para o mercado de trabalho. ${ }^{14}$

Portanto, nesse contexto da inscrição do negro no mercado de trabalho brasileiro, em que se percebe, através dos estudos referenciados, que os traços fenotípicos servem para sua identificação racial e seu status ocupacional que perguntamos: qual a cor dos oficiais na PMBA? Quem de que "cores" tem mais acesso aos cargos de destaque na estrutura organizacional, a exemplo do comandante geral e do chefe da Casa Militar do governador?

\section{A Polícia Militar da Bahia}

A Polícia Militar da Bahia foi criada através do Decreto Imperial de 17 de fevereiro de 1825. Sua estrutura já surge moldada com características militares de comando e nas operações, e com o objetivo de conter as graves tensões na Província da Bahia, já que os movimentos de libertos e escravos ameaçavam o modelo escravocrata. ${ }^{15}$

Da Colônia à República, a PMBA, em diferentes momentos de sua história, esteve vinculada ao Exército Brasileiro, seja na perspectiva jurídica ou operacional, para ser empregada como Força Auxiliar. No período militar, foi submetida à Doutrina da Segurança Interna e Territorial, sob o controle da IGPM - Inspetoria Geral das Polícias, atuando de forma centralizada e seletiva, como tropa de repressão ostensiva e velada sob o comando de oficiais do Exército. ${ }^{16}$

Durante as três últimas décadas, a instituição passou por modi-

14 Antonio Sergio Guimarães, Classes, raças e democracia, São Paulo: Fundação de Apoio à Universidade de São Paulo, 2002; Carlos Hasenbalg, Discriminação e desigualdades raciais no Brasil, Rio de Janeiro: IUPERJ, 2005.

15 Iacy Maia Mata, “Os 'treze' de maio: ex-senhores, polícia e libertos na Bahia no pós- Abolição (1888-1889)" (Dissertação de Mestrado, Universidade Federal da Bahia, 2002).

16 Martha K Huggins, Polícia e política: relações Estados Unidos / América Latina, São Paulo: Cortez, 1998. 
ficações na sua estrutura organizacional, ${ }^{17}$ para se adaptar à realidade da sociedade em processo de redemocratização, contudo, será possível ver a PMBA como uma instituição porosa, acessível à presença dos afro-descendentes nas patentes, ou restringindo a sua acessibilidade e mobilidade? Eis algumas das questões que norteiam nossa investigação na polícia fardada baiana.

\section{O ingresso}

Na década de oitenta, o acesso dos candidatos a oficial da PMBA se realizava por processo seletivo conduzido internamente pela Polícia Militar, consistindo de uma prova intelectual, com etapas de um teste psicológico, avaliação social, teste físico e médico. Somente a partir da metade da década de noventa, o processo seletivo dos oficiais deixou de ser um procedimento inter corpus, para ter uma universalidade das oportunidades de acesso, como preceitua a Constituição Federal, unificando a seleção com o vestibular da Universidade Estadual da Bahia - UNEB. ${ }^{18}$

Antes da unificação do vestibular, as avaliações da "boa aparência", através da fotografia ou pessoalmente, além do "pedido", ${ }^{19}$ definiam o postulante a carreira de oficial, como destaca um informante:

Mas se escolhia normalmente o pedido, não era qualquer pedido, a depender também da cara do camarada. Aí ele disse assim: não me peça por preto. Mas o cara era preto, rapaz. Mas ele tinha que ver a fotografia antes. Aí tinha um branco, com suplente. (Cap. A.A.S.).

Portanto, segundo o informante, as fotografias dos candidatos, além das propriedades físico-anatômicas, tinham implicações sociais e simbólicas, ${ }^{20}$ de modo que a aparência e a cor do individuo na socieda-

17 Para uma consulta das modificações na estrutura da PMBA e sua legislação própria, ver Roberto Aranha, Legislação Policial Militar, São Paulo: Garamond, 2003.

18 BRASIL, Constituição da República Federativa do Brasil, In: James Alberto Siano (org.), (São Paulo: Rideel, 2000). A competência das polícias militares está prevista no $\S 4^{\circ}, 5^{\circ}$ do Art.144 da Constituição Federal; o ingresso no serviço público está previsto no inciso II do Art. 37, do mesmo diploma legal.

19 "Pedido" significava uma solicitação pessoal de um padrinho político ou pessoa ligada aos integrantes da PMBA, que desejavam patrocinar o ingresso de um parente/pessoa de sua relação por meio das formas relacionais.

20 Olívia Maria Gomes da Cunha, Intenção e gesto pessoa, cor e a produção da (in) diferença no Rio de Janeiro, 1927 - 1942, Rio de Janeiro: Arquivo Nacional, 2002. 
de brasileira permitem estabelecer as diferenças de status (posições sociais); incorporam "direitos", privilégios de tratamento legal, associados a um status da cor, ${ }^{21}$ visão esta referendada por outro informante:

Agora você me chamou a atenção para um fato interessante, inclusive tem algumas figuras na polícia que ficaram conhecidas pelo poder que tinham para indicar ou contra-indicar alguém para ingressar na corporação em todos os níveis, na época que a seleção era feita pela própria corporação, [...]. Existiam, assim, tradições familiares em ingressar na corporação, realmente (Cel. PM A.J.F.M.: aspirante em 1975).

As formas de discriminação e o preconceito também se manifestavam durante o curso de formação dos oficiais, pois o tratamento dispensado aos mais escuros restringia sua participação no espaço de socialização na instituição. Havia valorização de uma "cor" em detrimento de outra; os portadores de caracteres negroides não se coadunavam com a "seleção preferencial", ${ }^{22}$ como podemos observar no depoimento abaixo:

Mas é verdade e historicamente se comenta isto, de que os negros e feios iam para sepultamentos, missa de sétimo dia; os brancos e louros iam para dançar valsa, os bonitos, bem afeiçoados, dançar valsa... Era uma prática, era uma prática que não se tornava pública, não era dita como verdadeira, mas se questionava, acontecia, era notório. (Cel. PM D.C.M.: aspirante em 1975).

Destaca ainda outro informante quanto ao sistema de desigualdades raciais, que se encarregava de reproduzir a inferioridade social, a PMBA se apresenta como uma instituição mais porosa que as Forças Amadas: ${ }^{23}$

${ }^{21}$ Estas impressões sociais das imagens nas fotografias mostram a forma sutil e sub-reptícia da carga dos marcadores raciais, como a cor da pele, a textura do cabelo, os formatos dos lábios e do nariz, que estruturam a hierarquia racial brasileira, como destacam: Antonio Sergio Guimarães, Preconceito e discriminação, São Paulo: Fundação de Apoio à Universidade de São Paulo/Ed. 34, 2004; Marvin Harris, Padrões raciais nas Américas, Rio de Janeiro: Civilização Brasileira,1967; Donald Pierson, Brancos e pretos na Bahia: estudo de contato racial, São Paulo: Companhia Editora Nacional, 1971.

22 Costa Pinto, O negro no Rio de Janeiro, pp. 87-124.

23 Thales de Azevedo, As elites de cor numa cidade brasileira: um estudo de ascensão social \& classes sociais e grupos de prestígio, Salvador: EDUFBA/EGBA, 1996. Segundo o autor, a Polícia Militar era mais acessível aos indivíduos de cor na constituição da tropa, e a alguns mulatos e pretos, devido à "promoção primitiva", ou seja, à indicação política, permitia-se que ascendessem ao oficialato, o que ficou mais difícil quando jovens de cor branca passaram a ver a carreira de oficial adquirir prestígio.Ver, em particular, pp.100-102. 
Eu já tive oportunidade de participar do Miss Bahia, do Miss Feira, na época em que aqueles concursos eram bem concorridos. E eu não me recordo na época de quem participou comigo, mas eu não vou mentir que havia um direcionamento para o pessoal de tez mais clara. Havia sim (Ten Cel. RR. PM C.A.S.M.: aspirante em 1972).

\section{A cor dos oficiais}

É fundamental destacar que a classificação da cor dos oficiais da PMBA não foge à complexidade da classificação racial brasileira. Sua terminologia se reveste de um continuиm, seja no que diz respeito a quem classifica a pessoa, seja nas "cores" atribuídas às pessoas identificadas nas fichas dos oficiais, ${ }^{24}$ já que não ocorre uma autoclassificação na instituição policial militar.

Muito embora as classificações das categoriais raciais brasileiras sejam controversas desde os Seiscentos e os Setecentos, como destacou Santos em relação às crianças enjeitadas, ${ }^{25}$ já naquela época a cor da pele remetia o indivíduo a um lugar socialmente pré-estabelecido; a pigmentação remetia à identificação pela "cor" ou pela "raça" ${ }^{26}$ as quais demarcam os referenciais espaciais, inclusive da forma de tratamento dispensado.

A cor, portanto, é uma categoria analítica, revestida de discriminação e desigualdades, em que a "aparência física" é associada a grupos "racializados", a exemplo das fichas dos policiais militares aqui estudados.

A identificação da "cor" dos oficiais da PMBA foi construída através das atas de conclusão do curso de formação e das fichas funcionais, catalogadas entre os anos de 1967 a 2005, contabilizando 1.908 oficiais, que foram formados nesse período.

${ }^{24}$ As fichas do Serviço de Identificação da PMBA trazem caracteres físicos individuais, como o registro da filiação, naturalidade, estado civil, posto ou graduação, caracteres de cútis, barba, olhos, tipo de cabelos, bigode, altura e anomalias, registradas pelo responsável pela identificação. Essa ação pode recair para um oficial ou praça da Corporação. Utilizamos primeiro as atas de formatura dos alunos da Academia da Policia Militar para produzir um "mapa racial" da PMBA.

25 Jocélio Teles dos Santos, "De pardos disfarçados a brancos poucos claros: classificações raciais no Brasil dos séculos XVIII-XIX”, Afro-Ásia, n. 32 (2005), pp.115-37.

26 Ver, por exemplo, Harris, Padrões raciais nas Américas; Pierson, Brancos e pretos na Bahia, pp.198-209; Edward Telles, Racismo à brasileira: uma nova perspectiva sociológica, Rio de Janeiro: Relume Dumará, 2003; Charles Wagley, Race et classe dans lê Brésil rural, Paris: Unesco, 1952; Guimarães, Preconceito e discriminação, p. 25. 
Tabela 1: A cor dos oficiais das turmas (1967 a 1969)

\begin{tabular}{lrrrrrrrrrrrrrrrrr}
\hline $\begin{array}{l}\text { Anos/ } \\
\text { Turma }\end{array}$ & Branca & \multicolumn{3}{c}{$\begin{array}{l}\text { Parda } \\
\text { clara }\end{array}$} & Parda & Morena & \multicolumn{1}{l}{$\begin{array}{l}\text { Parda } \\
\text { escura }\end{array}$} & \multicolumn{1}{c}{ Preta } & \multicolumn{1}{c}{$\begin{array}{c}\text { Não } \\
\text { identificados }\end{array}$} & Totais \\
\hline & $\mathrm{N}^{\circ}$ & $\%$ & $\mathrm{~N}^{\circ}$ & $\%$ & $\mathrm{~N}^{\circ}$ & $\%$ & $\mathrm{~N}^{\circ}$ & $\%$ & $\mathrm{~N}^{\circ}$ & $\%$ & $\mathrm{~N}^{\circ}$ & $\%$ & $\mathrm{~N}^{\circ}$ & $\%$ & $\mathrm{~N}^{\circ}$ & $\%$ \\
1967 & 5 & 16 & 7 & 22 & 10 & 31 & 0 & 0 & 2 & 6 & 0 & 0 & 8 & 25 & 32 & 0 \\
1968 & 5 & 13 & 5 & 13 & 12 & 32 & 5 & 4 & 4 & 11 & 0 & 0 & 7 & 18 & 38 & 100 \\
1969 & 0 & 0 & 3 & 10 & 6 & 19 & 6 & 19 & 0 & 0 & 0 & 0 & 16 & 52 & 31 & 100 \\
Total & 10 & 10 & 15 & 15 & 28 & 28 & 11 & 11 & 6 & 6 & 0 & 0 & 31 & 30 & 101 & 100 \\
\hline
\end{tabular}

Fonte: Atas de formatura e ficha de identificação da PMBA.

$\mathrm{N}^{\circ}$ : quantidade de oficiais.

É relevante trazer os dados que mostram a classificação da cor dos oficiais, pois enquanto cadetes, foram submetidos ao processo seletivo interna corpus, antes da década de setenta. Os dados da tabela 1 mostram uma presença de cadetes com pigmentações diferenciadas, com certo equilíbrio entre as cores e os caracteres mais próximos do modelo europeu. Contudo, vemos que os oficiais de cor mais pigmentada, como os pardos escuros, ainda que estejam presentes, sua frequência é menor, enquanto os de cor preta estão ausentes. Esses indicadores permitem presumir que os estereótipos operavam como restrição à "entrada" de candidatos mais pigmentados, atingindo principalmente aqueles com caracteres negroides.

O resultado dessa amostra de 101 oficiais, no período entre os anos de 1967 a 1969, aponta para uma forte representatividade dos indivíduos de cor miscigenada, entretanto, percebe-se que os oficiais de caracteres vistos como próprios do europeu têm maior representatividade individual, como os de cor branca, com $10 \%$, os de cor parda clara, com $15 \%$, e, na outra ponta da escala cromática, os de cor parda escura, com $6 \%$, e os pretos não conseguiram acesso aos quadros da PMBA, nos últimos anos da década de 60.

Temos no centro do continuum das cores um significativo percentual de oficiais portadores de caracteres, que demarcam a intermistura racial com alguns componentes da adscrição suavizados, de modo que os pardos são $28 \%$ e os de cor morena, $11 \%$, totalizando $39 \%$ de mestiços, o que aponta o grau de miscigenação na PMBA, à época. 
Assim, muito embora possamos perceber esse grau de miscigenação na corporação militar estadual baiana naquele período, alguns oficiais apontam uma restrição de cadetes caracterizados pelos traços do fenótipo do negro, como afirma um oficial da época:

Na minha turma? O mais escuro? Acho que era eu. Eu e Eraldo. Não sei se você sabe... Eu acho que na minha turma era assim. Depois, os mais claros, e tinha os intermediários entre eu e os mais claros, mas nós não tínhamos, assim, um companheiro mais escuro, assim completamente negro não... Assim, a composição era essa (Cel. PM J.L.V.M.: aspirante em 1965).

Se é possível perceber uma presença de cadetes de traços negroides e total ausência de pretos, podemos especular que o preconceito operava de maneira sutil e sub-reptícia. De certa forma, havia um padrão estético mesmo com o registro de oficiais miscigenados, mas com traços mais próximos aos do europeu. Significa reconhecer que a noção da "beleza" do tipo europeu permeava as representações na seleção dos candidatos, diversa das características do negro ou de seus descendentes diretos, como sinaliza um oficial formado à época:

Na minha turma não teve negro não. Nenhum negro. Mulato, mas negro não tinha. Dizem que a academia dos oficiais, um pouco antes, tinha essa preocupação. Porque, na época, só tinha oficiais brancos. Na fundação da academia, a primeira turma, de 1941. A primeira turma foi em 1941 ou 1943? A primeira turma não tem. A segunda turma tem Nestor, mais pinçado. Inclusive teve turma que só teve branco. Eles tinham essa preocupação com a cor. (Cel. PM A.S.P.B.: aspirante em 1961).

Certamente entre os oficiais da Academia da Polícia Militar, formados nos anos citados, as oportunidades para a inserção de candidatos mais escuros foram positivas para os indivíduos miscigenados. A ausência de oficiais da cor preta ("pinçado"), segundo o informante acima, e a "preocupação com cor" sinalizam algum tipo de restrição, porém, já se percebe o acesso de indivíduos pigmentados ou com certo grau de mestiçagem, que aponta a PMBA como receptiva com sinais de ser uma "organização tradicionalmente popular". ${ }^{27}$

27 Azevedo, As elites de cor numa cidade brasileira, p. 101. 
A amostra compreendida no período de dez anos (Tabela 2) é composta de 353 oficiais, totalizando dez turmas no curso de formação na Academia da Polícia Militar. Vemos, na tabela, que os oficiais de cor parda $(23,5 \%)$ e os pardos claros $(23,2 \%)$ tiveram a maior participação na composição racial, seguidos dos da cor morena $(17,6 \%)$, dos da cor branca $(13,0 \%)$, dos pardos escuros $(7,6 \%)$ e, por último, dos de cor preta $(0,3 \%)$.

Assim, a distribuição das "cores" nas turmas de formação de oficiais ao longo desse tempo registra uma presença de oficiais miscigenados com os indivíduos mais pigmentados, no centro do continuum das diversas categorias de "cores". Assim, os pardos, os pardos claros e os morenos juntos correspondem a 64,3\%; há uma frequência dessas categoriais de cores em todas as turmas de formação, nos vários anos da década, mas essa presença se rompe em relação aos pardos escuros, que, nos anos de 1977 e 1980, não tiveram oficiais nas turmas da cor preta, que só teve representante no ano de 1973.

Essa composição racial, com uma tendência ascendente de intermistura das cores dos oficias, mostra uma porosidade crescente na centralidade do continuum, pois mesmo a cor morena (categoria não oficial do IBGE), que inclui conotações e variantes de características físicas, podemos especular que a presença dos oficiais mais pigmentados já se registrava à época:

Não era regra. Não era um padrão. Porque branco seria o Camerino, eram Jackson, Silva, Evangelista. Ah! tinha Lopes. Lopes também era negro. Então tinha. Eram mais ou menos uns 12 oficiais. Dos 12, eu creio que três eram negros (...) (Cel. PM A.J.F.M.: aspirante em 1975).

Reforçando a visão do oficial acima, outro integrante da turma de 1976 que vivenciou as experiências acadêmicas declara: "Mas nós temos afrodescendente: Eu, Manuelito, Josafá, Veloso. Veloso não, eu Manuelito, Josafá, mas eram poucos" (Cel. PM N.R.M.: aspirante em 1976).

Tinha alguns brancos, tínhamos alguns brancos... Mas a turma era metade. Meio a meio. A intermistura racial se acentua nessa década, com a significativa presença de indivíduos de caracteres ambíguos, os pardos 
e os morenos que formam o continuиm racial brasileiro, o qual acomoda outras categoriais, formando um "guarda-chuva racial. ${ }^{28}$

$\mathrm{Na}$ outra ponta da classificação, os brancos e os pardos claros com suas características mais próximas do caucasoide formam outro segmento importante no contexto racial da polícia fardada baiana.

Tabela 2. A cor dos oficiais das turmas (1970 a 1980)

\begin{tabular}{|c|c|c|c|c|c|c|c|c|c|c|c|c|c|c|c|c|}
\hline \multirow[t]{2}{*}{$\begin{array}{l}\text { Anos/ } \\
\text { Turma }\end{array}$} & \multicolumn{2}{|c|}{ Branca } & \multicolumn{2}{|c|}{$\begin{array}{l}\text { Parda } \\
\text { clara }\end{array}$} & \multicolumn{2}{|c|}{ Parda } & \multicolumn{2}{|c|}{ Morena } & \multicolumn{2}{|c|}{$\begin{array}{l}\text { Parda } \\
\text { escura }\end{array}$} & \multicolumn{2}{|c|}{ Preta } & \multicolumn{2}{|c|}{$\begin{array}{c}\text { Não } \\
\text { dentifica do: }\end{array}$} & \multicolumn{2}{|c|}{ Totais } \\
\hline & $\mathrm{N}^{\circ}$ & $\%$ & $\mathrm{~N}^{\circ}$ & $\%$ & $\mathrm{~N}^{\circ}$ & $\%$ & $\mathrm{~N}^{\circ}$ & $\%$ & $\mathrm{~N}^{\circ}$ & $\%$ & $N^{\circ}$ & $\%$ & $\mathrm{~N}^{\circ}$ & $\%$ & $\mathrm{~N}^{\circ}$ & $\%$ \\
\hline 1970 & 4 & 16,0 & 2 & 8,0 & 10 & 40,0 & 3 & 12,0 & 1 & 4,0 & 0 & 0,0 & 5 & 20,0 & 25 & 100 \\
\hline 1971 & 5 & 16,7 & 8 & 26,7 & 8 & 26,7 & 3 & 10,0 & 1 & 3,3 & 0 & 0,0 & 5 & 16,7 & 30 & 100 \\
\hline 1972 & 3 & 9,7 & 9 & 29,0 & 6 & 19,4 & 4 & 12,9 & 4 & 12,9 & 0 & 0,0 & 5 & 16,1 & 31 & 100 \\
\hline 1973 & 5 & 9,3 & 15 & 27,8 & 4 & 7,4 & 10 & 18,5 & 7 & 13,0 & 1 & 1,9 & 12 & 22,2 & 54 & 100 \\
\hline 1974 & 9 & 15,8 & 12 & 21,1 & 10 & 17,5 & 15 & 26,3 & 2 & 3,5 & 0 & 0,0 & 9 & 15,8 & 57 & 100 \\
\hline 1975 & 4 & 10,8 & 8 & 21,6 & 13 & 35,1 & 9 & 24,3 & 3 & 8,1 & 0 & 0,0 & 0 & 0,0 & 37 & 100 \\
\hline 1976 & 6 & 15,0 & 10 & 25,0 & 12 & 30,0 & 1 & 2,5 & 6 & 15,0 & 0 & 0,0 & 5 & 12,5 & 40 & 100 \\
\hline 1977 & 3 & 11,1 & 7 & 25,9 & 11 & 40,7 & 5 & 18,5 & 0 & 0,0 & 0 & 0,0 & 1 & 3,7 & 27 & 100 \\
\hline 1978 & 3 & 9,7 & 6 & 19,4 & 5 & 16,1 & 10 & 32,3 & 3 & 9,7 & 0 & 0,0 & 4 & 12,9 & 31 & 100 \\
\hline 1980 & 4 & 19,0 & 5 & 23,8 & 4 & 19,0 & 2 & 9,5 & 0 & 0,0 & 0 & 0,0 & 6 & 28,6 & 21 & 100 \\
\hline Total & 46 & 13,0 & 82 & 23,2 & 83 & 23,5 & 62 & 17,6 & 27 & 7,6 & 1 & 0,3 & 52 & 14,7 & 353 & 100 \\
\hline
\end{tabular}

Fonte: Atas e formatura e fichas de identificação da PMBA.

$N^{\circ}$ : Quantidade de oficiais.

\section{A cor dos oficiais das turmas (1981 a 1991)}

A amostra desse período (Tabela 3) compreende um total de 552 oficiais pesquisados, sendo que de 126 desses não foram localizadas as fichas com suas características, ou seja, $23 \%$ da análise.

Assim, os dados apontam que $10 \%$ são oficiais da cor branca, $18 \%$, pardos claros, $27 \%$, pardos, $14 \%$, morenos, $7 \%$, pardos escuros e $1 \%$, pretos.

28 Telles, Racismo à brasileira, pp.104-8. Nessa obra, o autor discute as contradições, a fluidez das categoriais raciais do Brasil, construídas pela incerteza da miscigenação, o ideal do branqueamento, que se apresenta na população, a associação à cor (traços fenótipos), às subcategorias raciais, além do status do individuo. 
No contexto das turmas de formação, verificamos que da cor branca, apenas no ano de 1984, não foi registrada a presença de nenhum oficial; no oposto, a parda escura, nos anos de 1982 e 1989, e a preta estiveram representadas nos anos de 1986 (3\%) e 1987 (2\%) no âmbito de cada turma.

De modo que a ausência dos indivíduos de cor parda escura em duas turmas não significa uma rejeição do acesso aos quadros da PMBA, pois, no ano de 1981, os oficiais pardos escuros representavam $18 \%$ na sua turma de formação de oficiais; em 1984, eram 11\%, em 1986, 10\%, respectivamente.

Os dados dessa amostra permitem observar que houve um aumento no número de oficiais na PMBA com caracteres miscigenados, inscrevendo em seus quadros, de forma tímida, indivíduos mais escuros (os pardos, os escuros e os pretos), sinalizando certa resistência de seu ingresso, pois, em números absolutos, os brancos representaram 53 oficiais, os pardos claros, 100, contra 7 pardos escuros e apenas 1 da cor preta.

Assim, na composição das turmas da década de oitenta, pode-se afirmar que os oficiais de fenótipos negroides (pretos), ainda que subrepresentados na amostra, chamavam a atenção com sua presença, como destaca um informante sobre sua turma: "É meio a meio. É meio a meio, mais ou menos. Não, não. Acho que... Poxa, agora dá pra recordar? Acho que dá: 30\% de negão" (Maj. PM J.J.N., aspirante em 1981).

Outro informa sobre a composição da cor em outra turma:

Não tinha negros nas duas turmas anteriores. Quando eu ingressei na academia, no primeiro ano, no segundo e no terceiro, não tinha negros. Não tinha. [Em relação à sua turma de formação afirma:] Apenas quatro. Hoje major Alfredo, major Paixão, Nilton Paixão e o tenente coronel do Bombeiro, André Bonfim. Negros mesmo. Dessa turma (Maj. PM A.F.R.S., aspirante em 1984).

\section{A cor dos oficiais das turmas (1993 a 2005)}

Nesse período (onze anos), essa amostra é constituída de 889 oficiais. Vemos os de cor branca (2\%) e os pardos claros (22\%) totalizando $22 \%$, em oposição a esses, os pardos escuros $(10 \%)$ e os pretos $(0,2 \%)$, juntos, 
Tabela 3: A cor dos oficiais das turmas (1981 a 1991)

\begin{tabular}{|c|c|c|c|c|c|c|c|c|c|c|c|c|c|c|c|c|}
\hline \multirow[t]{2}{*}{$\begin{array}{l}\text { Anos/ } \\
\text { Turma }\end{array}$} & \multicolumn{2}{|c|}{ Branca } & \multicolumn{2}{|c|}{$\begin{array}{c}\text { Parda } \\
\text { clara }\end{array}$} & \multicolumn{2}{|c|}{ Parda } & \multicolumn{2}{|c|}{ Morena } & \multicolumn{2}{|c|}{$\begin{array}{l}\text { Parda } \\
\text { escura }\end{array}$} & \multicolumn{2}{|l|}{ Preta } & \multicolumn{2}{|c|}{$\begin{array}{c}\text { Não } \\
\text { identificado }\end{array}$} & \multicolumn{2}{|c|}{ Tot ais } \\
\hline & $\mathrm{N}^{\circ}$ & $\%$ & $\mathrm{~N}^{\circ}$ & $\%$ & $\mathrm{~N}^{\circ}$ & $\%$ & $\mathrm{~N}^{\circ}$ & $\%$ & $\mathrm{~N}^{\circ}$ & $\%$ & $\mathrm{~N}^{\circ}$ & $\%$ & $\mathrm{~N}^{\circ}$ & $\%$ & $\mathrm{~N}^{\circ}$ & $\%$ \\
\hline 1981 & 4 & 14 & 1 & 4 & 8 & 28 & 3 & 11 & 5 & 18 & 0 & 0 & 7 & 25 & 28 & 100 \\
\hline 1982 & 6 & 30 & 1 & 5 & 5 & 25 & 7 & 35 & 0 & 0 & 0 & 0 & 1 & 5 & 20 & 100 \\
\hline 1983 & 4 & 17 & 3 & 13 & 4 & 17 & 6 & 24 & 2 & 8 & 0 & 0 & 5 & 21 & 24 & 100 \\
\hline 1984 & 0 & 0 & 11 & 31 & 12 & 33 & 4 & 11 & 4 & 11 & 0 & 0 & 5 & 14 & 36 & 100 \\
\hline 1985 & 7 & 15 & 7 & 15 & 10 & 21 & 14 & 30 & 1 & 2 & 0 & 0 & 8 & 17 & 47 & 100 \\
\hline 1986 & 10 & 9 & 28 & 25 & 42 & 39 & 10 & 9 & 11 & 10 & 3 & 3 & 6 & 5 & 110 & 100 \\
\hline 1987 & 6 & 15 & 6 & 15 & 18 & 43 & 4 & 10 & 2 & 5 & 1 & 2 & 4 & 10 & 41 & 100 \\
\hline 1988 & 6 & 15 & 9 & 22 & 12 & 29 & 3 & 7 & 3 & 7 & 0 & 0 & 8 & 20 & 41 & 100 \\
\hline 1989 & 1 & 2 & 11 & 21 & 16 & 31 & 11 & 21 & 0 & 0 & 0 & 0 & 13 & 25 & 52 & 100 \\
\hline 1990 & 3 & 9 & 9 & 27 & 4 & 12 & 5 & 16 & 3 & 9 & 0 & 0 & 9 & 27 & 33 & 100 \\
\hline 1991 & 6 & 5 & 14 & 12 & 25 & 21 & 9 & 8 & 6 & 5 & 0 & 0 & 60 & 49 & 120 & 100 \\
\hline Total & 53 & 10 & 100 & 18 & 156 & 27 & 76 & 14 & 37 & 7 & 4 & 1 & 126 & 23 & 552 & 100 \\
\hline
\end{tabular}

Fonte: Atas de formatura e fichas de identificação da PMBA.

$\mathrm{N}^{\circ}$ : quantidade de oficiais.

Tabela 4: A cor dos oficiais das turmas (1993 a 2005)

\begin{tabular}{|c|c|c|c|c|c|c|c|c|c|c|c|c|c|c|c|c|}
\hline \multirow[t]{2}{*}{$\begin{array}{l}\text { Anos/ } \\
\text { Turma }\end{array}$} & \multicolumn{2}{|c|}{ Branca } & \multicolumn{2}{|c|}{$\begin{array}{c}\text { Parda } \\
\text { clara }\end{array}$} & \multicolumn{2}{|c|}{ Parda } & \multicolumn{2}{|c|}{ Morena } & \multicolumn{2}{|c|}{$\begin{array}{l}\text { Parda } \\
\text { escura }\end{array}$} & \multicolumn{2}{|l|}{ Pr eta } & \multicolumn{2}{|c|}{$\begin{array}{c}\text { Não } \\
\text { identificador }\end{array}$} & \multicolumn{2}{|c|}{ Tot ais } \\
\hline & $\mathrm{N}^{\circ}$ & $\%$ & $\mathrm{~N}^{\circ}$ & $\%$ & $\mathrm{~N}^{\circ}$ & $\%$ & $\mathrm{~N}^{\circ}$ & $\%$ & $\mathrm{~N}^{\circ}$ & $\%$ & $\mathrm{~N}^{\circ}$ & $\%$ & $\mathrm{~N}^{\circ}$ & $\%$ & $\mathrm{~N}^{\circ}$ & $\%$ \\
\hline 1993 & 8 & 13 & 13 & 22 & 22 & 36 & 1 & 2 & 11 & 18 & 1 & 2 & 4 & 7 & 60 & 100 \\
\hline 1994 & 3 & 5 & 13 & 22 & 27 & 44 & 3 & 5 & 7 & 12 & 1 & 2 & 6 & 10 & 60 & 100 \\
\hline 1995 & 0 & 0 & 13 & 28 & 12 & 26 & 1 & 2 & 1 & 2 & 0 & 0 & 20 & 42 & 47 & 100 \\
\hline 1996 & 0 & 0 & 14 & 41 & 15 & 44 & 1 & 3 & 1 & 3 & 0 & 0 & 3 & 9 & 34 & 100 \\
\hline 1997 & 2 & 7 & 2 & 7 & 6 & 22 & 8 & 31 & 7 & 26 & 0 & 0 & 2 & 7 & 27 & 100 \\
\hline 1999 & 0 & 0 & 10 & 29 & 13 & 37 & 0 & 0 & 1 & 3 & 0 & 0 & 11 & 31 & 35 & 100 \\
\hline 2000 & 0 & 0 & 6 & 23 & 18 & 69 & 0 & 0 & 2 & 8 & 0 & 0 & 0 & 0 & 26 & 100 \\
\hline 2001 & 0 & 0 & 30 & 39 & 11 & 14 & 2 & 3 & 15 & 19 & 0 & 0 & 19 & 25 & 77 & 100 \\
\hline 2002 & 1 & 0 & 50 & 20 & 126 & 52 & 1 & 0 & 21 & 8 & 0 & 0 & 49 & 20 & 248 & 100 \\
\hline 2004 & 0 & 0 & 19 & 12 & 113 & 73 & 1 & 1 & 12 & 8 & 0 & 0 & 9 & 6 & 154 & 100 \\
\hline 2005 & 0 & 0 & 27 & 22 & 83 & 69 & 0 & 0 & 8 & 7 & 0 & 0 & 3 & 2 & 121 & 100 \\
\hline Total & 14 & 2 & 197 & 22 & 446 & 50 & 18 & 2 & 86 & 10 & 2 & 0 & 126 & 14 & 889 & 100 \\
\hline
\end{tabular}

Fonte: Atas de formatura e fichas de identificação da PMBA.

$\mathrm{N}^{\circ}$ : quantidade de oficiais. 
constituíam 10,2\% do total analisado. No centro das "cores", os oficiais de cor parda representam 50\%, seguidos da cor morena com 2,0\%.

Nesse sentido, com o crescimento da população negra, nesse intervalo, e o acesso ao moderno mercado de trabalho na capital baiana, ${ }^{29}$ a carreira de oficial da PMBA não representou um significativo ingresso dos indivíduos mais miscigenados às patentes de oficial, pois indivíduos de caracteres raciais herdados do africano são pouco presentes no conjunto das cores, diferente dos pardos e dos morenos, cuja combinação de caracteres físicos controversos, juntos foram maioria dos oficiais, isto é, $52 \%$ da amostra, como vemos na tabela 4.

Os dados revelam a consolidação da escolha da carreira policial militar como alternativa de ascensão social para os indivíduos miscigenados, ainda que se perceba pouca representação dos com caracteres negroides. A hipótese para essa forte presença de indivíduos de caracteres fisionômicos controversos na carreira de oficial da PMBA pode decorrer da atração pela estabilidade funcional, pelo acesso a plano de saúde (médico e odontológico), pela aposentadoria, pelo status de oficial e pelo valor simbólico da patente, ${ }^{30}$ pois os brancos e os pardos claros já estavam inscritos no quadro da oficialidade baiana.

Assim, a diminuição da presença de oficiais de cor branca de 10\% (1981-1991) para 2\%, no período de onze anos, chama atenção, pois é possível conjeturar que os candidatos de "cor" branca não vissem a PMBA como atrativa para mobilidade social ou o processo de avaliação do vestibular pela UNEB serviu como seleção positiva para os que estavam mais qualificados intelectualmente.

Essa diminuição da presença de indivíduos com fenótipos europeus em sete turmas, de forma contínua e alternada, contrasta com a presença dos oficiais pardos escuros em todo período; as taxas significativas de $18 \%$ (1993), 26\% (1996), e, no ano de 2001, com $8 \%$, encerrando o período da amostra com $7 \%$ contra nenhum registro de oficiais

29 Bacelar, A hierarquia das raças, pp.188-195.

30 A Carta Patente prevista no Decreto n. 29.036, de 10 de agosto de 1992, é o documento expedido ao oficial quando promovido ao primeiro posto dos subalternos (tenente) e ao primeiro posto de superior, o qual reconhece os direitos, a honra, as regalias e as vantagens da carreira. 
de "cor" branca, o que pode sustentar nosso argumento, que, ao se tornar transparente, o processo seletivo da APM, com os candidatos de "cor" qualificados, o mérito intelectual permitiu que indivíduos mais pigmentados se tornassem oficiais da PMBA.

Por certo, com base nesses indicadores, o acesso universalizado do processo seletivo do vestibular, instituído pela Corporação na segunda metade da década de noventa, constituiu-se fator positivo para o ingresso dos afro-descendentes, pois as ingerências de "escolhas" pela aparência ou por indicações já não tinham força, a partir do referido período, como afirmam nossos informantes:

Eu acho que talvez o divisor de águas esteja aí. Na nossa época, quando existia o curso preparatório de alunos, você ingressava no curso preparatório de alunos, ou oriundo do Colégio da Polícia Militar ou oriundo do mundo civil, ou oriundo da tropa. Tudo através de seleção interna. Não era um processo seletivo aberto ao público de um modo geral. E quem fazia as provas era a própria polícia. $\mathrm{Na}$ academia, da mesma forma. Os concursos eram realizados pela polícia militar. Essa vinculação ao vestibular da UNEB, isso é uma coisa relativamente recente (Cel. PM A.J.F.M.: aspirante em 1975).

Essa forte presença de oficiais miscigenados na PMBA pode ser atribuída à busca de um capital cultural, ${ }^{31}$ que possibilitasse compensar a baixa origem social e a desvantagem competitiva; ${ }^{32}$ historicamente identificada como entraves à mobilidade ascendente, como aponta um informante:

Minha primeira morada mesmo foi em Cosme de Farias. Em Cosme, eu morava numa casa, numa ladeira, a Ladeira da Fonte de Santo Antônio, Morava numa casa, que era uma avó. Quatro casas e um sanitário coletivo. Meu pai era motorista de táxi, à época e minha mãe costurava roupa, bem como espichava cabelo. E daí nós fomos crescendo, meu pai arrumou emprego na CHESF de motorista e daí foi evoluindo... (Maj. PM J.J.N., aspirante em 1981).

31 Pierre Bourdieu, A economia das trocas simbólicas, São Paulo: Perspectiva, 1974.

${ }^{32}$ Carlos S. Hasenbalg, Discriminação e desigualdades raciais no Brasil. 
Um segundo informante destaca sua origem rural e a forma de subsistência familiar antes de ingressar na PM baiana:

Minha mãe era doméstica, dona de casa. Meu pai, ele era pequeno negociante, se ligava mais nessa parte da agricultura e pecuária, mas tinha também um armazém pequeno lá em São Sebastião (Cel. PM J.L.V.M.: aspirante em 1965).

Outro informante enfatiza a condição civil da mãe e destaca a educação como uma via importante para ascensão social:

Eu sou filho de mãe solteira. Eu só vim ter um relacionamento mais forte, intimo, com meu pai a partir dos 19 anos de idade, depois de formado. Nunca tive uma aproximação assim maior com ele. Morei até os 14 anos em palafitas, que são casas construídas em cima d'água, aquela coisa toda. E o meu grande diferencial foi a possibilidade que eu tive de concluir meus estudos (Maj. PM L.R.O.M., aspirante em 1986).

Já o terceiro, também informante, no posto de coronel destaca a origem social dos seus pais: "Meu pai era pedreiro e minha mãe bordadeira, e ambos trabalhavam para a subsistência da família" (Cel. A.A.F.: aspirante em 1971).

\section{A distribuição das cores no poder da PMBA}

A PMBA não pode ser vista livre dos efeitos dos preconceitos raciais e do corporativismo na sociedade. As manifestações do preconceito de marca revelam critérios subjetivos de quem observa e daquele que é julgado para ter acesso às posições sociais, como destacou Nogueira, ${ }^{33}$ principalmente quando as oportunidades de acesso não são universalizadas pelos interesses individuais ou corporativos, como destaca um informante:

Eu acho que, naquela época, principalmente, eu via assim, o concurso como um concurso feito para os filhos de oficiais, principalmente oficiais coronéis da Polícia Militar, aqueles realmente que queriam ingressar na Corporação. Mas se discutia assim, nos bastidores, esse movimento, en-

33 Oracy Nogueira, Tanto preto quanto branco: estudos de relações raciais, São Paulo: T.A. Queiroz, 1985. 
tendeu? Porque é aquela história, eu não vou ser assim precipitado em dizer que existia trambique no concurso. Mas é claro pra você que, às vezes, em concursos feitos por entidades especializadas em concursos acontecem às fraudes, imagine em concursos feitos internamente, dentro da Corporação. Prova. Tudo. Correção de prova. Naquela época, não se existia muita fiscalização. Quem fiscalizava o próprio concurso era a própria Corporação. Quantos filhos de oficiais tinham (...). A tendência era ter alguma influência, o fato de algum camarada ter um filho, o cara era coronel da Polícia, tinha um filho prestando concurso, pouquíssimas vagas (...) (Maj. PM A.F.R.S., aspirante em 1984).

Portanto, na dinâmica racial brasileira, alguns indivíduos mais pigmentados com nuanças negroides, por vezes conseguem transpor as barreiras raciais e a falta de oportunidades, todavia, a cor da pele e a dimensão cultural, histórica e social remetem a uma origem racial de maneira depreciativa, ancorada na aparência dos indivíduos.

Nesse sentido, a aparência e a cor inscrevem o individuo em um status, com a incorporação de alguns "direitos", na forma de privilégios de tratamentos legal ou não, porém, sempre associado a um status da cor, ${ }^{34}$ entretanto, os efeitos da adscrição racial restringem a ocupação de posições sociais proeminentes. É o que dizem dois de nossos informantes:

Rapaz, esse negócio de preconceito racial sempre existiu. E, em nosso tempo, também não se escapava. Sempre existiu, mas eu nunca liguei, entendeu? Embora eu seja preto, nunca dei bola... Para mim não existia isto... (CEL. PM J.S.F.: aspirante em 1948).

Eu tive notícias, eu tive notícias de que muitos companheiros, por terem a tez negra, eram preteridos na sua ascensão funcional. E tem um caso até de um excelente capitão, um homem inteligentíssimo, e que ele limitou-se a chegar ao posto de capitão, e não quis fazer o Curso de Aperfeiçoamento de Oficiais. De lá ele completou o tempo e foi pra reserva. Um homem de uma capacidade intelectual muito grande. Hoje é falecido. (Ten. Cel. PM RR C.A.S.M.: aspirante em 1972).

Superar o preconceito, ainda que dissimulando suas manifestações internamente para alcançar as patentes, como de coronel, era uma

34 Guimarães, Preconceito e discriminação, pp. 23-7. 
forma de superar a desvantagem competitiva. Desse modo, dos oficiais formados nas turmas nos anos de 1970 a 1978, num total de 353, apenas 36 conseguiram chegar à patente de coronel, ${ }^{35}$ resultando na composição racial vista na tabela abaixo:

Os dados apontam que a oficialidade superior, no último posto da PMBA, é composta de indivíduos caracterizados como mestiços, contudo, as características raciais hereditárias estão mais próximas dos traços fisionômicos do europeu. Observa-se a presença de $19 \%$ da cor morena (07 oficiais), categoria racial com nuanças fluidas, e dos pardos com $39 \%$ (14 oficiais), cuja categoria se revela com alto grau de ambiguidade na sua miscigenação.

Já os oficiais com menor grau de mestiçagem, mais próximos da tez europeia, a cor branca com 6\% (02 oficiais) e a parda clara é representada com $28 \%$ (10 oficiais), que juntas são um total de $34 \%$, dados que revelam uma mobilidade funcional mais receptiva a essas duas categorias raciais. É possível identificar uma ideologia saturada de preconceito, relacionada a um lugar racializado, como afirma um coronel pardo escuro:

Uma equipe de São Paulo estava fazendo uma reportagem sobre o carnaval. E me ligaram. Quem me ligou foi da Bahia que me conhecem e tal, mas eu não sabia que era uma equipe de São Paulo que faria esta reportagem comigo. Eu fui para esse local. Lá um cidadão disse que estava esperando o coronel (...) para fazer uma reportagem a nível nacional. Eu digo: - Infelizmente o Cel. não vai mais fazer a reportagem não, porque ele já está aqui. Aí foi desculpa de um lado, desculpa para outro... Não posso fazer uma leitura se o coronel que eles estavam querendo era um coronel gordão, ou se era a cor da pele mesmo (Cel. PM ex-comandante do policiamento da região leste da Bahia).

É possível, então, apontar, com base nos dados da tabela 5, que existe uma porosidade na ascensão funcional de mestiços na PMBA, ainda que as diferentes combinações das características físicas aparentes sejam a cor da pele, enquanto o principal atributo restritivo. Vemos

35 As promoções na PMBA decorrem dos critérios de antiguidade (classificação por mérito intelectual no curso de formação) e merecimento (desempenho profissional), após julgamento da comissão de promoção são referendadas pelo governador do Estado. Para concorrer ao posto de coronel, observa-se apenas o critério de merecimento. 
Tabela 5: A cor dos coronéis promovidos nas turmas (1970 a 1978)

\begin{tabular}{lrr}
\hline Cores & $\mathbf{N}^{\circ}$ & $\%$ \\
\hline Branca & 2 & $6 \%$ \\
Parda Clara & 10 & $28 \%$ \\
Parda & 14 & $39 \%$ \\
Morena & 7 & $19 \%$ \\
Parda Escura & 3 & $8 \%$ \\
Preta & 0 & $0 \%$ \\
Não Identificada & 0 & $0 \%$ \\
Total & 40 & $100 \%$ \\
\hline Fol
\end{tabular}

Fonte: Atas de formatura e ficha de identificação da PMBA. $\mathrm{N}^{\circ}$ : quantidade de oficiais.

os pardos escuros presentes com $8 \%$ (3 oficiais) e a categoria racial preta sem nenhum representante. Os pardos com 39\% (14 oficiais) e os da cor morena com 19\% (7 oficiais); cores dotadas de ambiguidades, que se afastam dos caracteres negroides e trazem significados sociais, ao sofrerem menor restrição de mobilidade para ascender à patente de coronel, por conseguirem se desvincular da marca do status racializado.

\section{A cor dos comandantes da Academia da PMBA}

A vida profissional do futuro oficial da PMBA ocorre através do curso de formação realizado na Academia de Polícia Militar. A sua gênese militar, ainda que de caráter provisório, surgiu em julho de 1935, em ato interno do comandante geral, mas, no mesmo ano o Governo do Estado da Bahia, por Decreto $n^{\circ} 9.731$, criou o Centro de Instrução Militar - CIM.

Juntamente com a formação dos oficiais, o mesmo prédio abrigava a formação e o aperfeiçoamento dos sargentos, sendo que, em 1940, passou a denominar-se Centro de Instrução Técnico Profissional - CITP; já, em 1948, passa a ser chamado Centro de Instrução da Polícia Militar - CIPM.

Naquele período, passou por algumas mudanças na sua denominação, como no ano de 1953 - passou a ser chamada Escola de Formação de Oficial - EFO e, por fim, em 1972, através do Decreto n 22.902, 
foi denominada Academia da Polícia Militar - APM - permanecendo este nome nos dias atuais. ${ }^{36}$

Desde 1938, com a transformação em Academia, passou-se a exigir o curso científico completo (atualmente ensino médio) para seu ingresso, porém, o recrutamento ocorria de maneira endógena. Somente em 1942, permitiu-se o ingresso de candidatos oriundos da sociedade civil. Posteriormente, em 1963, foram recrutados alunos egressos do Colégio da Polícia Militar, que obtivessem avaliações com boas notas nas disciplinas, no teste físico e no psicológico.

Não obstante tais nuanças no seu recrutamento, os candidatos eram diferenciados na sua formação, que se constituía de dois quadros: o intendente e o combatente. O primeiro, com abordagem acadêmica na gestão, enquanto o segundo, além desse aspecto, enfatizava o planejamento e a execução do policiamento ostensivo.

Com a extinção do quadro de intendente, essa dicotomia passa a permear a visão de mundo dos alunos ditos armamentistas e dos não armamentistas, ${ }^{37}$ os primeiros contrários à utilização das artes marciais, defendendo o uso das armas para resolução das ocorrências, enquanto outro segmento sustentava e era favorável à reflexão através das disciplinas da administração, do direito e das ciências sociais.

Tais considerações em relação à formação do futuro oficial vão além das salas de aula da APM. Ela não é somente a "porta de entrada" do oficialato, mas o espaço acadêmico de qualificação para aquisição do mérito intelectual, como requisito para a mobilidade nas patentes. Nesse sentido, todos os oficiais e os futuros comandantes, além da formação acadêmica, são submetidos aos rituais de passagem pelo intenso processo de socialização em diferentes momentos da vida profissional. ${ }^{38}$

Além da visibilidade interna, a Academia da Polícia Militar recebe alunos e oficiais de outras instituições policiais militares nos seus di-

${ }^{36}$ Major Oséas Moreira de Araújo, Notícias sobre a Polícia Militar da Bahia no século XIX, Salvador: Polícia Militar da Bahia, 1997.

37 Carlos F. Linhares de Albuquerque, "Escola de Bravos: cotidiano e currículo numa Academia de Polícia Militar" (Dissertação de Mestrado, Universidade Federal da Bahia, 2000).

${ }^{38}$ Celso de Castro, O espírito militar: um antropólogo na caserna, Rio de Janeiro: Jorge Zahar Ed., 2004. 
versos cursos de formação e especialização, projetando a imagem institucional fora do território estadual; de modo a permitir que seu comandante seja percebido, na dimensão social e simbólica, como o profissional responsável pela qualidade da preparação integral dos oficiais baianos. ${ }^{39}$

Portanto, a ocupação do cargo de comandante da APM se destaca no contexto interno e externo da PMBA pela sua representatividade institucional e pessoal. Desse modo, na tabela 6, verificamos que 33\% dos comandantes eram da cor branca; os pardos claros, $14 \%$; os oficiais da cor morena 24\%; já os da cor parda escura representam $10 \%$ da amostra de 21, que comandaram a APM.

Tais indicadores sobre as cores desses oficiais demonstram que, durante trinta e cinco anos, vemos uma predominância dos indivíduos de caracteres de epiderme miscigenados (os pardos, os morenos, os pardos escuros), que, juntos, significam 53\% da amostra; os indivíduos de caracteres mais próximos do modelo europeu, os de cor branca e os pardos claros, somados, representam $47 \%$.

Ainda que se identifique uma predominância dos oficiais miscigenados, percebe-se, no contexto da instituição, que se apresenta como mestiça, certa tendência não consolidada por indivíduos de tez mais clara. Uma explicação para esses percentuais dos oficiais de epiderme clara se refere à representatividade social e simbólica, pois o cargo confere uma identidade "branqueada", ${ }^{40}$ ou seja, uma combinação de raça, classe e gênero, como percebeu D’Ávila na ocupação do cargo de professores na cidade do Rio de Janeiro.

\section{A cor dos comandantes da PMBA.}

Ascender na sociedade brasileira não significa para os indivíduos ocupar cargos de visibilidade. A discriminação e o preconceito raciais possuem mecanismos suavizados de manutenção do status, diferenciando não a pertença social, mas a cor ou a raça, utilizados como certos "direitos", vistos como inerentes a alguns grupos sociais.

39 Bourdieu, O poder simbólico, pp. 7-16.

40 Jerry Dávila, Diploma de brancura: política social e racial no Brasil - 1917-1945, São Paulo: Ed. UNESP, 2006, pp.147-98. 
Como o Estado, a PMBA está inserida na estrutura da Secretaria da Segurança Pública; espraia suas atribuições nas diversas atividades na preservação da ordem pública e, como gestor maior tem um coronel de carreira que ocupa o cargo de comandante geral.

Portanto, a visibilidade que tal função atribui ao coronel permite que este se relacione com diferentes membros da alta administração do Estado, com os Poderes Judiciário e Legislativo, além de várias autoridades nas esferas Municipal, Estadual e Federal.

Através dos dados coletados de quatorze oficiais que conseguiram ocupar o cargo de comandante geral da PMBA, no período de 1970 a 2005 , identificamos $29 \%$ dos oficiais de cor branca, a parda clara com $14 \%$. No meio do continuum da escala cromática, os oficiais de cor parda representam $22 \%$, enquanto os da cor morena são representados por $14 \%$. $\mathrm{Na}$ outra ponta, temos os oficiais de cor parda escura, representados com $21 \%$, sem que tenha havido registro de oficiais da cor preta no comando da PMBA, no intervalo de trinta e cinco anos, conforme tabela abaixo.

Aqui devemos ressaltar que a nomeação dos comandantes da PMBA passa pela escolha do governador, portanto, a ocupação da função é outorgada por avaliações subjetivas do nomeante. Nesse sentido, a presença de oficiais de cor clara, com 29\%, e os pardos, com 14\%, assegura uma destacada presença, ainda que "as linhas divisórias entre brancos e pardos são pouco nítidas", ${ }^{41}$ revelando uma tendência a associar os últimos à cor branca. De sorte que reconhecemos, através das representações dos governantes, uma segregação da cor dos mais escuros, mesmo com a presença de oficiais de cor parda escura e morena ocupando tal função.

A ocupação da função de destaque e status como a de comandante geral da PMBA, para oficiais mais escuros representa não só a superação do seu nível de preparo profissional, mas, como aponta Telles, ${ }^{42}$

${ }^{41}$ Edward Telles, "Identidade racial, contexto urbano e mobilização política". Afro-Ásia, n. 17 (1996), p.126.

42 Apud Nelson do Valle Silva, "Updating the Cost of Not Being White in Brazil", in Pierre M. Fontaine (org.) Race, Class and Power in Brazil (Los Angeles: UCLA Center for Afro-American Studies,1985), pp. 42-55; Peggy Lovell, Income and Racial Inequality in Brazil (Tese de Doutorado, Universidade da Flórida,1989). 
Tabela 6: A cor dos comandantes da APM (1970 a 2005)

\begin{tabular}{lcc}
\hline Cores & $\mathbf{N}^{\circ}$ & $\%$ \\
\hline Branca & 7 & $33 \%$ \\
Parda Clara & 3 & $14 \%$ \\
Parda & 4 & $19 \%$ \\
Morena & 5 & $24 \%$ \\
Parda Escura & 2 & $10 \%$ \\
Preta & 0 & $0 \%$ \\
Não Identificada & 0 & $0 \%$ \\
Total & 21 & $100 \%$ \\
\hline
\end{tabular}

Fonte: Atas de formatura e ficha de identificação da PMBA. $N^{\circ}$ : Quantidade de oficiais.

Tabela 7: A cor dos comandantes gerais da PMBA (1970 a 2005)

\begin{tabular}{lcc}
\hline Cores & $\mathbf{N}^{\circ}$ & $\boldsymbol{\%}$ \\
\hline Branca & 4 & $29 \%$ \\
Parda Clara & 2 & $14 \%$ \\
Parda & 3 & $22 \%$ \\
Morena & 2 & $14 \%$ \\
Parda Escura & 3 & $21 \%$ \\
Preta & 0 & $0 \%$ \\
Não Identificada & 0 & $0 \%$ \\
Total & 14 & $100 \%$ \\
\hline
\end{tabular}

Fonte: Atas de formatura e ficha de identificação da PMBA. $N^{\circ}$ : Quantidade de oficiais.

que os negros e os pardos sofrem níveis semelhantes de discriminação racial no mercado de trabalho, nesse sentido um desses oficiais sinaliza a existência do preconceito racial ao afirmar:

A discriminação está ai, ela existe. Mas, no meu consciente, ela existe, vai existir por muito tempo, mas eu vou passar por cima dela que nem um trator. Aquele que se puser no meu caminho com esse tipo de ato vai se capar, que eu vou trucidar. É o sistema. Ele esta ai para isso, o sistema é assim, ele é que nem a seleção natural, se você é forte, você sobrevive, se você for fraco, você morre... (Maj. PM L.R.O.M., integrante do Grupamento Aéreo da PMBA). 
Tabela 8: A cor dos chefes da Casa Militar (1970 a 2005)

\begin{tabular}{lcc}
\hline Cores & $\mathbf{N}^{\circ}$ & $\%$ \\
\hline Branca & 5 & $29 \%$ \\
Parda Clara & 1 & $14 \%$ \\
Parda & 4 & $22 \%$ \\
Morena & 2 & $14 \%$ \\
Parda Escura & 2 & $21 \%$ \\
Preta & 0 & $0 \%$ \\
Não Identificada & 0 & $0 \%$ \\
Total & 14 & $100 \%$ \\
\hline
\end{tabular}

Fonte: Atas de formatura e ficha de identificação da PMBA. $N^{\circ}$ : Quantidade de oficiais.

\section{Cor dos chefes da Casa Militar do governador da Bahia}

A Casa Militar do governador da Bahia é um órgão de assistência, assessoria e representação, com diversas atribuições na estrutura burocrática do governo, e, entre outras atividades, deve executar a segurança ostensiva e reservada do governador, de autoridades em diferentes níveis como a dos dignitários (chefes de Estado e governos). ${ }^{43}$

A escolha do titular dessa função também obedece a critérios políticos e à qualificação profissional, principalmente quanto à confiança que estrategicamente a função exige. Sua indicação é um ato volitivo do governador do Estado ou pode ser oriunda da de alguma autoridade que preencha tal perfil.

$\mathrm{Na}$ escolha de oficial de "confiança", temos dois de cor parda escura que aparecem na amostra, entretanto a ocupação da função foi temporária, ou seja, responderam de forma cumulativa pela titularidade, enquanto o governador da época escolhia um novo ocupante para o cargo.

A amostra desse cargo compreende 14 oficiais, que estão distribuídos com $29 \%$ na cor branca, $14 \%$ de parda clara, o que significa a

${ }^{43}$ Roberto Aranha, Legislação Policial Militar. Ver, em particular, o Decreto no 834, de 19/12/ 1991. 
presença de oficiais revestidos de caracteres mais próximos do caucasoide; no meio do continuum da escala cromática, a cor morena tem $14 \%$, e os de cor parda escura, $21 \%$, entretanto, os oficiais pardos escuros, na realidade, não foram efetivados como titulares da função; e não se registra nenhum oficial de cor preta nomeado para chefia da Casa Militar do Governo da Bahia, em três décadas e meia.

Aqui podemos apontar que existe uma tendência negativa para a presença dos oficiais mais escuros na Chefia da Casa Militar. Há um efeito através do sistema de valores e dos padrões estéticos que demandavam para qualificação da aparência, que talvez não se coadune com um mestiço de traços negroides, como aponta um informante:

Esse lá é padrão diferente. Lá é... Isso sempre foi observado, não sei se pela tradição lá na Casa Militar, mas sempre foi colocado como um local de representação. Num local de representação, você não tem negro. Não existe isso, essa cultura de colocar negro. O único gabinete que você vai encontrar negros é no meu aqui. É cultura geral... (Cel. PM A.J.R.S.: ex-comandante geral da PMBA).

\section{Considerações finais}

A partir dos dados construídos por esse "mapa racial", podemos verificar que a PMBA pode ser vista como uma instituição composta por uma oficialidade mestiça. O ingresso de indivíduos de "cor" ou mais pigmentados se inicia nos quadros de oficiais, a partir do final da década de 60, e distribui-se ao longo dos trinta e cinco anos, mas não significou uma absorção equilibrada dos indivíduos oriundos dos segmentos mais populares de origem étnico-racial descendente dos africanos.

Vimos que o ingresso de candidatos na PMBA ocorria com um processo seletivo de forma endógena. Com a universalidade do processo seletivo, o vestibular da UNEB e as práticas discriminatórias da "indicação" ou do "apadrinhamento", mitigadas por algumas atitudes segregacionistas e preconceituosas como de marca, ${ }^{44}$ permitiram de forma restritiva o ingresso de indivíduos de fenótipos da cor parda, escura e preta.

${ }^{44}$ Nogueira, Tanto preto quanto branco, pp.79-80. 
Assim, a noção de "cor" como um atributo do status social dos candidatos a oficial permite associar as posições sociais que demarcavam a origem popular dos oficiais da PMBA. Os oficiais viam na PMBA uma instituição porosa, que sinalizava o ingresso e a mobilidade social já que um significativo número de mestiços conseguiu ascender nas patentes e nos cargos de destaque, como o de comandante geral.

Essa agência fardada da ordem pública tem como destaque o cargo de comandante geral, que significa o ápice da carreira do oficialato baiano. Dentre outros cargos ocupados pelos oficiais, a Casa Militar do governador - CMG e o de diretor e comandante da APM apresentam uma representatividade social e simbólica.

Ainda que o cargo de comandante geral seja o ápice da carreira do oficialato baiano, não podemos deixar de registrar que as ações repressivas estão associadas ao seu comandante e não ao governo. As ações repressivas (políticas) contra os movimentos sociais e pelo restabelecimento pelo Estado Democrático de Direito sempre foram, de forma ostensiva, das agências fardadas. Na contemporaneidade, com o agravamento da violência urbana na cidade de Salvador e das ações criminosas, medidas repressivas de combate ao narcotráfico levaram a identificar práticas policiais violentas de agressões a cidadãos e com "vitimizações" de inocentes.

É certo que todas essas ações instrumentais e simbólicas recaem na instituição que tem como responsável o comandante da PMBA. Diferente do chefe da Casa Militar, que tem atribuições de visibilidade positiva, pois não lida com a prevenção e a repressão dos atos criminosos, nem contra os movimentos sociais; sua ação restringe-se à proteção física do governador e da representatividade junto às instâncias governamentais em diferentes níveis da burocracia Estatal, portanto, não pode ser vista como um instrumento objetivado do poder Estatal, o chefe da Casa Militar atua, diria, nos bastidores do poder.

Assim, diferentes percepções raciais podem ser atribuídas aos ocupantes desses dois cargos. A composição racial dos oficiais que chegaram à patente de coronel, nos anos de 1970 a 1978, 8\%, foi de pardos escuros, nenhum preto, $6 \%$ brancos e $28 \%$ pardos claros. Esses dados demonstram a consequente alocação como uma manifestação própria 
do racismo brasileiro: absorver indivíduos de caracteres mais próximos do "padrão europeu". Os indivíduos miscigenados com traços mais afastados dos sinais diacríticos dos mais escuros são os mais absorvidos simbolicamente da ordem racial vigente.

A representatividade e a visão de mundo dos oficiais mestiços e escuros apontam que existiam algumas manifestações de racismo na PMBA. Foi possível, então, identificar um resquício de uma seleção preferencial (preconceito) operada em relação aos candidatos mais pigmentados na década de sessenta; uma escolha promovida de forma isolada, não institucional, porém, quando o candidato tinha traços fenótipos mais negros, se avaliava a origem social e de status do padrinho.

A presença de indivíduos mestiços (pardos, morenos, pardos escuros) ao longo dos trinta e cinco anos da pesquisa aponta que o ingresso na carreira de oficial da PMBA é vista, por um considerável segmento da população baiana, como uma alternativa de mobilidade social.

Essa opção pela Força Militar Estadual é demonstrada por alguns aspectos atrativos: a estabilidade no emprego, a ascendência funcional, a mudança do status e as possibilidades reais de aquisição de outras qualificações externas à Corporação, como cursos de graduação. Os indivíduos, os futuros oficiais mestiços, veem na PMBA oportunidades de ascensão social, que não foram disponibilizadas às suas gerações, como uma forma de escapar das desvantagens sociais, culturais e simbólicas.

Assim, este estudo permite apontar a PMBA como uma instituição composta de oficiais mestiços. A restritiva presença do preto e a baixa representatividade dos pardos escuros repercutem na ocupação dos cargos de destaque na Força Militar Estadual, o cargo de comandante geral com menor restrição pelas características da hierarquização social e simbólica, já o cargo de chefe da Casa Militar do governador da Bahia mantém o tradicional sistema de status e raça, como a cor e o "fino trato", como representações do legado da civilização europeia.

Texto recebido em 10/10/2010 e aprovado em 28/6/2011 


\title{
Resumo
}

Este artigo aborda, principalmente, a relação entre ascensão social e cor. São enfatizadas algumas abordagens centrais, como a biografia dos informantes, a trajetória acadêmica policial militar, a percepção do racismo desde a condição de cadete e a distribuição dos oficiais na patente de coronel através das categorias raciais que ascendem aos cargos de maior importância na instituição militar estadual. A metodologia se baseou na coleta e entrevistas do tipo survery, que resultou no "mapa racial dos oficiais baianos", no período de 1970 a 2005.

Palavras-chave: discriminação racial - ascensão social - racismo - Polícia Militar da Bahia

\begin{abstract}
This paper examines the relationship between color and social ascension among the military police of Bahia, taking into consideration the life history of individual members of the police force, their trajectories in the police academy and their perceptions of racism dating back to their days as a cadet. It also presents data on the racial classification of officials holding the rank of colonel or higher. The data were obtained via questionnaires, yielding a "racial map of Bahian officials" over the period 1970-2005.
\end{abstract}

Keywords: racial discrimination - social ascension - racism - Military Police (Bahia) 